21. Сергушина О.В., Евсеева Ю.А. Значение дидактических игр на уроках в начальной школе // Азимут научных исследований: педагогика и психология. 2014. № 4. С. 56-57.

22. Платонова Т.Е. Система психолого-дидактических задач и соответствующих приемов обучения // Карельский научный журнал. 2013. № 4. С. 84-86.

23. Яковлева Е.Л. Многообразные облики игры: попытка философского осмысления // Азимут научных исследований: педагогика и психология. 2014. № 3. C. 87-90.

24. Макеева Е.Д. Использование образовательных технологий в процессе преподавания дисциплины
«Естественнонаучная картина мира»// Поволжский педагогический вестник. 2015. № 1 (6). С. 21-25.

25. Чаговец А.И. Дидактический аспект профессиональной подготовки будущих воспитателей ДУЗ // Азимут научных исследований: педагогика и психология. 2015. № 2 (11). С. 116-119.

26. Макеева Е.Д. Методика оценки результатов освоения дисциплины «Естественнонаучная картина мира» // Современные технологии подготовки кадров и повышения квалификации специалистов нефтегазового производства: тезисы Международной научнопрактической конференции. В.К. Тян (отв. редактор), М.В. Петровская (отв. секретарь). 2014. С. 74.

\title{
DIDACTIC GAME \\ AS A WAY OF CREATING ENVIRONMENTAL AWARENESS AMONG STUDENTS
} (C) 2016

\author{
E.V. Lizunova, candidate of pedagogical sciences, \\ associate professor of Biology, Ecology and Methods of Teaching Department \\ Samara State University of Social Sciences and Education, Samara (Russia)
}

Abstract. Currently mankind needs to change attitudes to nature and ensure the upbringing and education of a new generation. The basis for mankind development should be a community of man and nature. Man needs new knowledge, new system of values that should be created and educated since childhood. In these circumstances ecological education and upbringing in the modern school should be a priority. On the level of ecological education, ecological culture depends on the question of humanity survival, a possibility of a person to stay on the planet. The system of formal and non-formal education includes a large amount of environmental knowledge and skills implementing the requirements towards the growth and development of ecological culture. This article focuses on the formation of environmental knowledge among schoolchildren in the framework of the optional course «Game-playing Ecology». Special attention in this matter is paid to didactic games as they have great teaching opportunities for formation of knowledge in the field of nature management and environmental protection. Properly constructed didactic game stimulates students' interest and attention, develops memory, self-regulation, thinking, reinforces knowledge, skills and abilities, trains touch skills, strong-willed qualities of the child.

Keywords: didactic game; games environment; schoolchildren; environmental education; environmental knowledge; experiment; roleplay; ecological literacy; environment; environmental education; pedagogical experiment; biology; teaching methods; elective course.

\section{УДК 378}

\section{ФОРМИРОВАНИЕ ЛИДЕРСКИХ КАЧЕСТВ У СТУДЕНТОВ}

(C) 2016

И.В. Никулина, кандидат педагогических наук, доцент кафедры теории и методики профессионального образования Самарский национальный исследовательский университет имени академика С.П. Королёва, Самара (Россия)

Аннотащия. В статье рассматриваются особенности лидерства в студенческой группе. Представлены трактовки феномена лидерства, существующие в отечественной и зарубежной литературе. Анализируется феномен ролевой дифференциации лидерства в группе. Описаны результаты исследования ролевой дифференциации лидерства в двух студенческих группах. Методом экспериментального сочинения был изучен феномен идентификации в лидерстве как механизм влияния лидера на последователей. Проанализировав результаты исследований ролевой дифференциации лидерства и идентификации в лидерстве, проведенных на одной и той же выборке студентов, приходим к выводу о том, что идентификация в группе происходит преимущественно с инструментальным или эмоциональным лидером, так как именно им приписывается наибольшее число идентификационных качеств. С помощью самоперцептивного опросника был изучен социально-перцептивный механизм развертывания идентификационного процесса в лидерстве. Результаты экспериментальных исследований показывают, что при формировании лидерских качеств у студентов необходимо учитывать особенности ролевой дифференциации в группе: инструментальный лидер организует студенческую группу на решение поставленной перед ней учебно-профессиональной задачи; эмоциональный лидер студенческого коллектива заботится о поддержании благоприятного психологического климата в группе, об укреплении групповой сплоченности.

Ключевые слова: лидерство; лидер; лидерские роли; лидерские качества; преподаватель; студент; студенческая группа; формирование лидерских качеств; ролевая дифференциация лидерства; эмоциональный лидер; инструментальный лидер; идентификация; идентификационные качества. 
В настоящее время предъявляются высокие требования к качеству профессиональной подготовки студентов. Ориентир делается на воспитание студента как саморазвивающейся, конкурентоспособной личности, готовой к лидерству и успешному выполнению своей профессиональной деятельности $[1 ; 2]$. В процессе обучения в вузе студент должен научиться не только принимать самостоятельные решения, но и нести ответственность за них. Осознавая тот факт, что ведущей целью педагогического процесса является развитие личности студента, формирование у него лидерских качеств, преподаватель должен организовывать учебно-воспитательный процесс, учитывая социально-психологические особенности лидерства.

Изучение феномена лидерства нашло отражение в работах Г.М. Андреевой [3], Р.Л. Кричевского [4], Л.И. Уманского [5], О.В. Евтихова [6], С.Р. Кови [7], Э. Берна [8], П.У. Бендера, Э. Хеллмана [9], М. Фридмана [10], Б. Трейси, Ф.М. Шеелена [11], Р. Дилтса [12], Дж. Максвелла [13], Ф.О. Хессельбайн [14], Д. Гоулмана [15], А. Менегетти [16] и других ученых. Лидерство является одним из уникальных феноменов общественной жизни, связанного с реализацией властных функций. В науке имеется несколько трактовок феномена лидерства. Согласно одной из них, лидерство - это сосредоточение групповых процессов, а лидер - это член группы, который интегрирует групповые процессы и отношения [4;6]. Лидерство рассматривается также как характеристика самой личности и порождаемых ею эффектов. С точки зрения данного подхода, лидер - это человек, обладающий наибольшим, сравнительно с другими членами группы, набором желательных черт личности и характера и побуждающий других к выполнению групповой задачи [4; 6]. Некоторые исследователи рассматривают феномен лидерства как искусство добиваться подчинения. С позиции данного подхода лидер может не учитывать потребности членов группы, а также традиции и нормы последней $[4 ; 6]$. Трактуя лидерство как форму убеждения, исследователь Р. Хоган рассматривает убеждение как важный инструмент влияния на ожидания и верования людей в политической, социальной и религиозных сферах жизни общества [4]. Рассматривая лидерство как процесс порождения структуры, исследователи обращают внимание на то, что лидерство - это активный процесс создания и поддержания ролевой структуры в групповом взаимодействии. По мнению Дж. Хемфилла, Ф. Фидлера, лидерство - это поведение индивида, вовлеченного в управление групповыми действиями, а лидерское поведение - это специфические действия, реализуемые лидером в процессе управления и координации работы членов его группы [4]. Точка зрения на лидерство как видение перспективы заключается в том, что лидер должен иметь перспективную программу действий, согласно которой он вместе с группой движется к намеченной цели. Он устремлен в будущее, имеет заманчивые для последователей планы и знание, как их реализовать. [6, с. 10].

Отечественными учеными (Г.М. Андреевой, Р.Л. Кричевским, Б.Д. Парыгиным и др.) лидерство трактуется как чисто психологический феномен, который возникает стихийно и существует в системе неформальных отношений людей [3; 4]. В основе лидерства лежит процесс межличностного влияния, возникающий между наиболее активным и влиятельным участником малой группы (лидером) и менее активными, ведомыми членами группы (последователями). Лидер инициирует групповые действия, направляет группу на решение стоящих перед ней задач [7; 16]. Последствия влияния в лидерстве отражаются в изменении точек зрения, поведения, отдельных личностных черт, установок, мотивации членов группы.

Одна из наиболее популярных трактовок лидерства связана с предположением о том, что лидерство есть один из аспектов процесса ролевой дифференциации в группе, выступающий в качестве функции динамического взаимодействия личных свойств и социальной системы. Изучение ролевой дифференциации лидерства впервые было предпринято исследователями Р. Бейлзом, Ф. Слейтером в работе с малыми группами, численностью до 6 человек, в которых не было лидера [3; 4]. В процессе эксперимента поведенческие реакции испытуемых фиксировались наблюдателями с помощью разработанной Р. Бейлзом схемы анализа взаимодействия, позволяющей зафиксировать 12 типов поведенческих реакций индивида в группе. Выделенные 12 типов поведенческих реакций были разделены на две группы: эмоциональные (позитивные и негативные эмоциональные реакции от процесса группового взаимодействия) и направленные на решение задачи (выдвижение собственных предложений по поводу решения задачи или активация других участников на поиск решения, подхват идеи участника и детальная ее разработка и т.п.). Исследователям удалось обнаружить в условиях эксперимента с малыми лабораторными группами наличие в группе двух фундаментальных лидерских ролей: делового или инструментального лидера и экспрессивного или эмоционального лидера, что получило название ролевой дифференциации лидерства. Учеными было доказано, что выделенные ими роли лидера связаны с различными аспектами функционирования группы. Роль делового или инструментального лидера направлена на решение стоящей перед группой задачи, а роль эмоционального или экспрессивного лидера направлена на усиление внутригрупповой интеграции. Р. Бейлз, Ф. Слейтер объясняли обнаруженный ими феномен ролевой дифференциации лидерства следующим образом: члены группы вносят неравный вклад в решение групповой задачи, субъект, наиболее инициативный в этой деятельности, является инструментальным лидером; остальные члены группы, осознавая факт неравенства вклада в групповую деятельность, начинают воспринимать инструментального лидера как источник напряжения, вызывающий у них фрустрацию. Для того, чтобы решить эмоциональные проблемы участников, группа выдвигает еще одного лидера - эмоционального или экспрессивного, задача которого заключается в создании благоприятного психологического климата внутригруппового взаимодействия [4].

Исследователи П. Секорд и К. Бекман высказали идею о том, что изменение ролевой дифференциации лидерства находится в прямой зависимости от успешности группы по решению задачи. Если члены группы не испытывают удовлетворения от процесса работы над задачей, то высока вероятность наличия в группе ролевой дифференциации лидерства. 
П. Берк, для объяснения феномена ролевой дифференциации лидерства, вводит понятие «легитимация деятельности по решению задачи», обозначающее то, что решение задачи группой есть одобряемая группой деятельность, а значит, ни один из членов группы не должен препятствовать ее осуществлению. В экспериментальных исследованиях П. Берк создавал различные условия легитимации деятельности, в результате чего он пришел к следующему выводу: ролевая дифференциация в группе проявляется при условии низкой легитимации деятельности по решению задачи. По мнению исследователя, в ситуации низкой легитимации деятельности активное участие делового лидера в решении задачи снижает его эмоциональную активность, в условиях же высокой легитимации снижение эмоциональной активности инструментального лидера не наблюдается, в результате чего он также выполняет роль эмоционального лидера [4].

В экспериментах Р.Л. Кричевского, проводившихся в естественных условиях, с естественными группами, было обнаружено, что ролевая дифференциация лидерства наблюдается и в условиях высокого уровня мотивации групповой деятельности, то есть в условиях высокой легитимации деятельности. В данных экспериментах не зафиксировано какого-либо антагонизма между инструментальными лидерами и другими членами группы, более того, инструментальные лидеры имели высокие оценки и по показателям эмоционального лидерства, бывали случаи, когда обе лидерские роли реализовывались одним лицом.

Эксперименты Л. Картера показали, что кроме двух фундаментальных лидерских ролей существуют еще и другие лидерские роли узкофункционального типа, возникающие в различных ситуациях групповой жизни, в зависимости от решения группой каких-либо специфических задач. Однако Л. Картер не дал обнаруженным в ходе эксперимента лидерским ролям какого-либо функционального названия. Это было сделано Л.И. Уманским, который описал следующие лидерские роли: лидер-организатор (интегрирует группу), лидер-инициатор (инициирует групповую деятельность), лидер - генератор эмоционального настроя (аналог роли экспрессивного лидера), лидерэрудит (специалист в решении интеллектуальных задач), лидер эмоционального притяжения (аналог «социометрической звезды»), лидер-мастер, умелец (хорошо выполняет какую-либо деятельность) [4].

Для того чтобы сформировать лидерские качества у студентов, преподавателю необходимо знать социально-психологические особенности лидерства. С целью изучения феномена ролевой дифференциации лидерства в студенческой группе нами было проведено исследование, направленное на выявление инструментальных и экспрессивных лидеров студенческой группы посредством ранжирования [20]. Выборку исследования (25 человек) составили студенты 3 и 4 курсов Самарского национального исследовательского университета имени академика С.П. Королёва специальности «Управление персоналом». Им предлагалось ответить на два вопроса, первый из которых был направлен на выявление инструментального лидерства: «Каков, по-твоему, вклад каждого члена твоей группы в успех учебной деятельности всей группы (т. е. кого бы из группы, включая и себя, ты поставил на первое место как самого успешного в учебной деятельности студента, кто был бы на втором месте, кто на третьем и т.д.)?» Второй вопрос касался эмоционального лидерства: «Каков, по-твоему, вклад каждого члена твоей группы в развитие дружеских отношений в группе (т.е. кого бы из группы, включая и себя, ты поставил на первое место как лучшего друга, кто бы оказался на втором месте, кто на третьем и т. д.)?» Лидерство в каждом из своих проявлений определялось суммированием баллов, полученных каждым членом студенческой группы от одногруппников при ранжировании. Студент с наилучшим показателем в баллах по каждому измерению группового лидерства рассматривается как лидер (деловой или эмоциональный). В результате проведённого нами исследования была обнаружена ролевая дифференциация лидерства в данных студенческих группах. Роли эмоционального и делового лидера выполняли разные люди, более того, эмоциональные лидеры даже не вошли в тройку лидеров по показателям инструментального лидерства [17].

Знания о существовании ролевой дифференциации лидерства помогут преподавателю грамотно выстроить учебно-воспитательный процесс в студенческой группе. Поддерживая и развивая у студентов качества инструментального лидера, преподаватель содействует повышению качества профессиональной подготовки, направляет студентов на эффективное решение учебно-профессиональных задач. Формируя у студентов качества эмоционального лидера, преподаватель способствует созданию благоприятного моральнопсихологического климата в студенческой группе, усиливает командный дух; развивает у студентов чувства эмпатии, взаимопомощи, поддержки.

Лидерство довольно часто в научной литературе рассматривается как процесс влияния, механизмом которого является идентификация $[3 ; 4 ; 18]$. Идентификация рассматривается как следование поведенческим или личностным характеристикам другого лица, как реальное их воспроизведение либо в сходных поведенческих актах, либо в символических эквивалентах поведения. Идентификация предполагает усвоение мотивации поступков значимого другого. Идентификация последователей с лидером определяется их представлениями о роли лидера, позволяющими принимать или не принимать определенного члена группы в качестве ее лидера; подразумевает наличие между ними психологических связей, влияющих на способности лидера оказывать влияние [4]. С целью изучения феномена идентификации в лидерстве нами было проведено второе исследование на той же самой выборке. Идентификация с одногруппником определялась методом экспериментального сочинения, в котором необходимо было описать черты характера и особенности поведения одногруппников, наиболее симпатичные испытуемому, и ответить на ряд вопросов: каким чертам характера и особенностям поведения одногруппников вы хотели бы следовать? Каково их реальное воспроизведение и в каких ситуациях? Замечали ли вы характерологические и поведенческие изменения под влиянием одногруппника? Не является ли кто-нибудь из одногруппников образцом для вас в 
Никулина И.В.

каких-либо поступках в той или иной ситуации? Не задумывались ли вы перед совершением поступка о том, как бы поступил в этом случае одногруппник, являющийся для вас образцом? Анализ экспериментальных сочинений позволяет выделить проявления идентификации с одногруппником, к которым относятся: стремление воспроизводить черты характера и особенности поведения своего одногруппника; поведенческие изменения под влиянием одногруппника, являющегося образцом для испытуемого; соотнесение собственного поведения в той или иной ситуации с воображаемым поведением одногруппника. При обработке сочинений из них выписываются все качества студентов, по которым отмечается идентификация (эти качества называются идентификационными). Фиксируется частота встречаемости качества и выясняется, сколько упоминаний приходится на долю каждого студента [17]. При обработке экспериментальных сочинений было выявлено, что идентификационными качествами в данных студенческих группах являются: ответственность (частота упоминания данного качества 66\%), отзывчивость (частота упоминания данного качества 53\%), доброта (частота упоминания данного качества 53\%), общительность (частота упоминания данного качества $51 \%$ ), веселый нрав (частота упоминания данного качества 34\%), активность (частота упоминания данного качества 27\%), дружелюбие (частота упоминания данного качества $24 \%$ ), пунктуальность (частота упоминания данного качества 17\%), старается помочь с выполнением заданий (частота упоминания данного качества 15\%), трудолюбие (частота упоминания данного качества 15\%), взаимопонимание (частота упоминания данного качества 15\%), непредвзятость (частота упоминания данного качества $15 \%$ ), честность (частота упоминания данного качества 15\%), открытость (частота упоминания данного качества 15\%), ум (частота упоминания данного качества 9\%), дисциплинированность (частота упоминания данного качества 8\%), забота о группе (частота упоминания данного качества 8\%), разносторонность (частота упоминания данного качества 8\%), безотказность (частота упоминания данного качества 8\%), грамотность (частота упоминания данного качества 8\%), умение найти подход к каждому человеку (частота упоминания данного качества 8\%), спокойствие (частота упоминания данного качества $8 \%)$ [17].

По мнению студентов, принявших участие в исследовании, инструментальный лидер обладает следующими качествами $[17$, с. 72$]:$ ответственность (частота упоминания данного качества 61\%), отзывчивость (частота упоминания данного качества 53\%), доброта (частота упоминания данного качества 50\%), дисциплинированность (частота упоминания данного качества 8\%), трудолюбие (частота упоминания данного качества 16\%), старается помочь с выполнением заданий (частота упоминания данного качества 33\%); веселый нрав (частота упоминания данного качества $33 \%$ ), активность (частота упоминания данного качества $18 \%$ ), пунктуальность (частота упоминания данного качества 16\%), ум (частота упоминания данного качества 10\%), разносторонность (частота упоминания данного качества 8\%). Эмоциональный лидер об- ладает следующими качествами: забота о группе (частота упоминания данного качества 35\%), отзывчивость (частота упоминания данного качества 30\%), веселый нрав (частота упоминания данного качества $26 \%$ ), умение найти подход к каждому человеку (частота упоминания данного качества 25\%), общительность (частота упоминания данного качества 20\%), доброта (частота упоминания данного качества 20\%), дружелюбие (частота упоминания данного качества $16 \%$ ), открытость (частота упоминания данного качества $16 \%$ ).

Сопоставление результатов исследований ролевой дифференциации лидерства и идентификации в лидерстве, проведенных на одной и той же выборке, позволило сделать следующий вывод: идентификация в группе происходит преимущественно с инструментальным или эмоциональным лидером, в подтверждении тому является тот факт, что именно лидерам приписывается наибольшее число идентификационных качеств. Анализируя идентификационные качества, выделенные студентами, преподаватель осознает внутренний механизм формирования поведения и личностных характеристик студентов. Он может использовать данную информацию при построении программы формирования лидерских качеств студента.

Процесс межличностной перцепции лежит в основе идентификации со значимым другим, в том числе и с лидером. У каждого человека есть некие эталонные качества, которые являются для него наиболее ценными. Если качества, являющиеся эталонными для субъекта, у него развиты слабо и он хотел бы их развить в будущем, а у группового лидера они сильно развиты, то в этом случае вероятна идентификация субъекта с лидером по значимым для него личностным и поведенческим параметрам. Изучению социально-перцептивного механизма развертывания идентификационного процесса в лидерстве было посвящено наше третье исследование, проведенное на той же самой выборке испытуемых. Студентам необходимо было ответить на вопросы самоперцептивного опросника, разработанного Р.Л. Кричевским: какие качества, черты характера ты особенно ценишь в людях? Как ты думаешь, какие из этих качеств, черт характера у тебя развиты слабо или совсем отсутствуют? Какие из отсутствующих или слабо развитых у тебя качеств, особенно тобой ценимых, ты хотел бы развить у себя в будущем? Какими, по-твоему, качествами, чертами характера должен обладать лидер студенческой группы? [4].

В результате проведенного исследования анализу подвергались пять рядов качеств: первый ряд - идентификационные качества, по которым происходит идентификация с одногруппником, взятые из экспериментальных сочинений; второй ряд - эталонные качества, которые являются особенно ценными для студентов данных групп; третий ряд - это качества, которые ценны для студентов, но у них слабо развиты; четвертый ряд - это качества, которые студенты планируют развить в будущем; пятый ряд - качества, которыми должен обладать лидер студенческой группы.

К эталонным качествам были отнесены: доброта (частота упоминания данного качества 61\%), ответственность (частота упоминания данного качества 
$53 \%$ ), активность (частота упоминания данного качества $41 \%$ ), веселый нрав (частота упоминания данного качества 40\%), честность (частота упоминания данного качества $31 \%$ ), отзывчивость (частота упоминания данного качества 24\%), умение вдохновлять (частота упоминания данного качества 24\%), открытость (частота упоминания данного качества 22\%), пунктуальность (частота упоминания данного качества 14\%), креативность (частота упоминания данного качества $13 \%$ ), сообразительность (частота упоминания данного качества $12 \%$ ), воля (частота упоминания данного качества 12\%), сдержанность (частота упоминания данного качества $12 \%$ ) [17, с. 73].

К слаборазвитым или отсутствующим эталонным качествам были отнесены: пунктуальность (частота упоминания данного качества 13\%), веселый нрав (частота упоминания данного качества 13\%), креативность (частота упоминания данного качества 13\%), сдержанность (частота упоминания данного качества $13 \%$ ), терпимость (частота упоминания данного качества 13\%), независимость (частота упоминания данного качества $13 \%$ ).

К качествам, которые студенты планируют развить в будущем, были отнесены: пунктуальность (частота упоминания данного качества 17\%), веселый нрав (частота упоминания данного качества 15\%), креативность (частота упоминания данного качества 14\%), сдержанность (частота упоминания данного качества 14\%), просчитывание ситуации (частота упоминания данного качества 13\%), независимость (частота упоминания данного качества 13\%).

К качествам, которыми должен обладать лидер студенческой группы были отнесены: ответственность (частота упоминания данного качества 53\%), уверенность в себе (частота упоминания данного качества $41 \%$ ), умение вдохновлять (частота упоминания данного качества 41\%), веселый нрав (частота упоминания данного качества 26\%), активность (частота упоминания данного качества 26\%), общительность (частота упоминания данного качества 24\%), открытость (частота упоминания данного качества $12 \%$ ), умение найти подход к каждому человеку (частота упоминания данного качества $11 \%$ ).

Данные, полученные с помощью самоперцетивного опросника и экспериментальных сочинений, показали, что некоторые качества, которые являются для студентов эталонными, одновременно являются и идентификационными. Некоторые из эталонных и идентификационных качеств совпадают с качествами, которыми должен обладать лидер студенческой группы. Полученные в процессе исследования материалы подтверждают доказанный отечественными психологами факт о том, что благодаря механизму идентификации осуществляется влияние лидера на последователей.

Результаты наших исследований показывают, что для того, чтобы сформировать лидерские качества у студентов, преподавателям необходимо учитывать особенности ролевой дифференциации в группе, идентификацию как механизм влияния в лидерстве. Инструментальный лидер организует группу на решение поставленной перед ней учебно-профессио- нальной задачи, эмоциональный лидер студенческого коллектива будет заботиться о создании благоприятного психологического климата в группе, об усилении внутригрупповой интеграции. Знания об идентификационных и эталонных качествах в лидерстве дают возможность преподавателю наиболее полно представить внутренние условия процесса межличностного влияния в студенческой группе и, следовательно, оказывать более эффективное воспитательное воздействие на студентов.

\section{СПИСОК ЛИТЕРАТУРЫ:}

1. Санько А.М. Факторы эффективности самостоятельной работы студентов в вузе // Профессиональное образование: проблемы, подходы, новации: сборник научных статей / под ред. Т.И. Рудневой. Самара: Институт анализа экономики города и региона, 2014. C. $80-85$.

2. Руднева Т.И. Педагогика профессионализма. Самара: Изд-во «Универс групп», 2008. 216 с.

3. Андреева Г.М. Социальная психология. М.: Аспект Пресс, 1996. 376 с.

4. Кричевский Р.Л. Психология лидерства. М.: Издательство «Статут», 2007. $541 \mathrm{c.}$

5. Чернышев А.С., Лунев Ю.А., Лобков Ю.Л., Сарычев С.В. Психологическая школа молодежных лидеров. М.: Московский психолого-социальный институт, 2005. $275 \mathrm{c}$.

6. Евтихов О.В. Эффективное лидерство. Красноярск: Сиб. гос. аэрокосмич. ун-т, 2012. 132 с.

7. Кови С.Р. Семь навыков высокоэффективных людей. СПб.: Питер, 2008. 202 с.

8. Берн Э. Лидер и группа: О структуре и динамике организаций и групп. Екатеринбург: Литур, 2000. 319 c.

9. Бендер П.У., Хеллман Э. Лидерство изнутри / Перевод с англ. Мн.: Попурри, 2005. 303 с.

10. Фридман М. Искусство и наука стратегии лидерства. Новый подход к корпоративному. управлению. М.: ГРАНД: Фаир-Пресс, 2004. 271 с.

11. Трейси Б., Шеелен Ф.М. Личность лидера / Перевод с англ. Мн.: Попурри, 2002. 288 с.

12. Дилтс Р. НЛП: навыки аффективного лидерства. СПб.: Питер, 2003. 224 с.

13. Максвелл Дж. 21 неопровержимый закон лидерства. Мн.: Попурри, 2002. 288 с.

14. Хессельбайн Ф.О лидерстве. Н.: ФСПИ «Тренды», 2004. 184 с.

15. Гоулман Д. Эмоциональное лидерство: Искусство управления людьми на основе эмоционального интеллекта. М.: Альпина, 2005. 301 с.

16. Менегетти А. Психология лидера /перевод с итальянского. ННБФ «Онтопсихология». Изд. 4-е, дополненное. М: ННБФ «Онтопсихология», 2004. 256 с.

17. Никулина И.В. Организация учебно-воспитательного процесса в студенческой группе с учетом особенностей лидерства // Профессиональное образование: проблемы, подходы, новации: сб. науч. статей; под ред. Т.И. Рудневой. Самара: Изд-во СГУ, 2014. С. $65-74$.

18. Психология лидерства: хрестоматия / сост. К.В. Сельченок. Мн.: Харвест, 2004. 368 с. 


\section{FORMATION OF LEADERSHIP QUALITIES IN STUDENTS}

(C) 2016

I.V. Nikulina, candidate of pedagogical sciences, associate professor of Theory and Methods of Professional Education Department

Samara National Research University, Samara (Russia)

Abstract. The following paper discusses the features of leadership in a student group. The author presents interpretations of leadership phenomenon that exist in domestic and foreign literature and analyzes the phenomenon of leadership differentiation role in a group. A phenomenon of leadership identification, as a mechanism of the leader influence on followers, is studied by the experimental method. As a result the author comes to the conclusion that the identification of the group takes place mainly with an instrumental or emotional leader, as a great number of identity attributes are ascribed to him/her. A self-perceptual questionnaire helps to study a social-perceptual mechanism of identification process deployment in leadership. The experimental results show that the formation of leadership qualities in students is necessary to consider the features of role differentiation in a group: the instrumental leader organizes a student group for the solution of educational and professional problems; the emotional leader takes care of favorable psychological climate maintenance in a group, strengthens the group cohesion.

Keywords: leadership; leader; leadership roles; leadership skills; teacher; student; student group; formation of leadership qualities; role differentiation of leadership; emotional leader; instrumental leader; identification; identification of quality.

УдК $37.034+378$

\section{НРАВСТВЕННОЕ ВОСПИТАНИЕ СТУДЕНТОВ В КУЛЬТУРНО-ОБРАЗОВАТЕЛЬНОМ ПРОСТРАНСТВЕ ВУЗА}

(C) 2016

С.В. Пупков, доктор педагогических наук, доцент, профессор кафедры социологии

Рязанский государственный университет имени С.А. Есенина, Рязань (Россия)

Аннотащия. В статье аргументируется необходимость осуществления нравственного воспитания студентов вуза как приобщения обучающихся к ценностям, находящимся в создаваемом преподавателем культурнообразовательном пространстве. Дополнено научное представление о понятии «образовательное пространство» и доказано, что содержательное наполнение понятие «культурно-образовательное пространство» получает через привлечение термина «культурный». Выявлена сущность культурно-образовательного пространства вуза, заключающаяся в его многомерности, которая выражается в бесконечности транслируемой через каналы образования и воспитания культуры как опыта деятельности, опыта духовно-практического освоения мира в морали, опыта нравственных, ценностных отношений по критерию предельного его (опыта) основания (ценность человека), благодаря которому субъект-объектные, объектно-субъектные и субъект-субъектные отношения становятся дополнительными. Раскрыто содержание культурно-образовательного пространства, образуемого субъект-объектными и субъект-субъектными отношениями, связь между которыми становится диалектической за счет объектно-субъектных отношений, в которых возникают ценности, являющиеся аксиологическим ядром деятельности, аксиологической формой культуры. Определено предназначение субъект-объектных и субъектсубъектных отношений как образующих содержание культурно-образовательного пространства и исходя из такого предназначения выявлены функции педагогической деятельности преподавателя, осуществляющего нравственное воспитание студентов: обеспечение хранения, воспроизводства, трансляции культуры как опыта деятельности, заключенного (опыта) в остенсивных, императивных, аксиологических формах культуры, ее формах-принципах; организация работы студентов с культурными формами; организация восхождения студента от аксиологических форм культуры к ее формам-принципам; передача опыта духовно-практического освоения мира в морали, опыта поведения и деятельности, опыта нравственных, ценностных отношений.

Ключевые слова: студент; преподаватель; вуз; воспитание; нравственное воспитание; пространство; культурно-образовательное пространство; ценность; отношение; субъект-объектные отношения; объектносубъектные отношения; субъект-субъектные отношения; сущность; содержание; функция.

Современный вуз функционирует в условиях социально-экономических перемен, происходящих в нашем обществе, затрагивающих все сферы его материальной и духовной жизни, влияющих на субъективную ценностную систему студентов. Одним из ведущих ориентиров развития общества становится жизнь, достойная человека. Однако сегодня идет размывание представлений о норме: все дозволено, каждый прав по-своему, что оборачивается оправданием любого порока. [1, с. 79]. «Если "все дозволено", подчеркивает В.Н. Сагатовский, - если главное - это наслаждение новизной, если нет ответственности и целое надо разрушать, а не развивать, сохраняя, то процессы социализации и индивидуализации имеют все шансы смениться процессом тотального развращения» $[1$, с. 83$]$. Выход из этой ситуации должен быть найден. Одним из возможных вариантов выхода является нравственное воспитание студентов вуза через их приобщение к ценностям, через организацию ценностно-ориентационной деятельности, являющейся способом осуществления ценностей, через развитие способности к морально-этической рефлексии, 